\title{
Pengaruh Dukungan Pendidikan, Sikap Dan Efikasi Diri Terhadap Intensi Kewirausahaan Pada Mahasiswa Semester Satu
}

\author{
Felicia Natali Liadi dan Herlina Budiono \\ Program Studi Manajemen Fakultas Ekonomi Universitas Tarumanagara, Jakarta \\ Email: felicia.115150432@stu.untar.ac.id
}

\begin{abstract}
The purposive of this research is to find out 1) whether is an effect of Perceived Educational Support on Entrepreneurship Intention 2) whether there is an effect of Attitudes on Entrepreneurship Intention 3) whether there is an effect of Self-Efficacy on Entrepreneurship Intention. Population in this research were first semester students in Economics Faculty of Management Tarumanagara University. The sample used in this research was 100 respondents from the students in Economics Faculty of Tarumanagara University. The sampling technique used was nonprobability sampling with piurposive sampling method. Overall the results of this research are 1) There is no significant effect of Perceived Educational Support on Entrepreneurship Intention, 2) There is a significant effect of Attitudes on Entrepreneurship Intention, 3) There is no significant effect of Self-Efficacy on Entrepreneurship Intention.
\end{abstract}

Keywords: Perceived Education Support, Attitudes, Self-Efficacy and Entrepreneurship Intention.

Abstrak: Tujuan penelitian ini adalah untuk mengetahui 1) apakah terdapat pengaruh Dukungan Pendidikan terhadap Intensi Kewirausahaan 2) apakah terdapat pengaruh Sikap terhadap Intensi Kewirausahaan 3) apakah terdapat pengaruh Efikasi Diri terhadap Intensi Kewirausahaan. Populasi pada penelitian ini ialah mahasiswa semester satu Fakultas Ekonomi Jurusan Manajemen Universitas Tarumanagara. Sampel yang digunakan pada penelitian ini berjumlah 100 responden mahasiswa Fakultas Ekonomi Universitas Tarumanagara. Teknik pengambilan sampel yang digunakan yaitu nonprobability sample dengan metode pengambilan sampel purposive sampling. Secara keseluruhan hasil dari penelitian ini yaitu 1) Tidak terdapat pengaruh yang signifikan Dukungan Pendidikan terhadap Intensi Kewirausahaan, 2) Terdapat pengaruh yang signifikan Sikap terhadap Intensi Kewirausahaan, 3) Tidak terdapat pengaruh yang signifikan Efikasi Diri terhadap Intensi Kewirausahaan.

Kata kunci: Dukungan Pendidikan, Sikap, Efikasi Diri, Intensi Kewirausahaan

\section{LATAR BELAKANG}

Kewirausahaan (entrepreneurship) merupakan salah satu faktor utama dalam dampaknya pembangunan ekonomi di suatu negara khususnya di Indonesia. Hal ini disebabkan kewirausahaan mempunyai kemampuan untuk menciptakan lapangan kerja, mengurangi pengangguran dan meningkatkan pendapatan masyarakat. Sebagian wirausaha juga berkontribusi kepada perekonomian negara melalui pajak yang dihasilkan. Salah satu masalah pengangguran adalah jumlah lapangan kerja yang tersedia lebih sedikit dibandingkan para pencari kerja, sehingga tidak dapat dipungkiri lagi bahwa banyak masalah keterbatasan 
kesempatan kerja bagi para lulusan perguruan tinggi. Salah satu alternatif yang dapat ditempuh untuk mengatasinya adalah dengan cara membuka peluang usaha yang baru yaitu dengan berwirausaha.

Menurut (Tempo.Co, 2013) "Kementerian Perekonomian mendorong agar pelajar dan mahasiswa menjadi bibit wirausaha. Sebab, para generasi muda ini memiliki nilai dan posisi yang strategis untuk membangun pertumbuhan ekonomi Indonesia. Pengembangan kewirausahaan di generasi muda merupakan keharusan untuk membuat Indonesia lebih maju dan mandiri." Salah satu perguruan tinggi di Jakarta yang telah menerapkan pendidikan kewirausahaan adalah Universitas Tarumangara. Pada mahasiswa Fakultas Ekonomi jurusan Manajemen dan Akuntansi diberikan pengajaran-pengajaran tentang kewirausahaan dari mata kuliah wajib yang harus diambil. Sedangkan mahasiswa jurusan manajemen lebih mendalam mempelajari kewirausahaan yaitu dengan dibukanya konsentrasi kewirausahaan. Mahasiswa diberikan mata kuliah wajib dan pilihan yang berkaitan tentang kewirausahaan, seminarseminar kewirausahaan, serta tugas-tugas dari mata kuliah tertentu yang membuat mereka memiliki pengetahuan dasar tentang kewirausahaan lebih dari mahasiswa-mahasiswa fakultas lainnya dan agar bisa menghasilkan lulusan yang kompeten, berintegritas, profesional, dan berjiwa entrepreneur. Oleh karena itu banyak perguruan tinggi saat ini giat membekali mahasiswanya dengan pendidikan entrepreneurship, baik dengan memasukkannya ke dalam kurikulum pendidikan yang wajib ditempuh oleh mahasiswa dan seminar-seminar yang berhubungan dengan entrepreneurship.

Di samping dukungan pendidikan, sikap juga berpengaruh dalam menumbuhkan jiwa berwirausaha karena agar mampu mengidentifikasi peluang usaha, kemudian mendayagunakan peluang usaha untuk menciptakan peluang kerja baru. Terkait dengan dukungan pendidikan dan sikap, tentunya diperlukan juga adanya efikasi diri yang diperlukan untuk menumbuhkan niat berwirausaha. Berwirausaha tentunya memerlukan efikasi diri (self efficacy). Efikasi diri yang didefinisikan sebagai kepercayaan diri atas kemampuannya dalam menyelesaikan pekerjaan, memegang peranan penting dalam mempengaruhi intensi seseorang. Efikasi diri terlihat dalam mempengaruhi perilaku dan kognisi seseorang. Efikasi diri diasosiasikan dengan peningkatan ekspektasi dan tujuan, peningkatan kinerja yang berkaitan dengan pekerjaannya (Sumarsono, 2016).

\section{KAJIAN TEORI}

Berdasarkan tujuan penelitian ini, maka teori yang digunakan ialah teori perilaku konsumen. Dasar teori untuk memaparkan teori perilaku konsumen ialah Theory of Reasoned Action (TRA) dan Theory of Planned Behavior (TPB). Seperti yang diketahui, bahwa perilaku konsumen dipahami sebagai bentuk atau perwujudan hasil dari keputusan konsumen yang didasarkan pada beberapa proses dan melibatkan integrasi pengaruh internal dan eksternal yang diterima konsumen. Dalam proses tersebut, sebelum menginjak pada tahap perwujudan hasil dari keputusan yang diambil, yaitu berupa perilaku pembelian, terdapat beberapa fase awal dalam aspek psikologis konsumen yang mengarahkan terwujudnya perilaku tertentu (Fishbein dan Ajzen, 1975). TRA dari (Fishbein dan Ajzen, 1975) menegaskan peran dari niat seseorang dalam menentukan apakah sebuah perilaku akan terjadi. Niat seseorang umumnya dipengaruhi oleh sikap-sikap terhadap suatu perilaku, seperti apakah dirinya merasa perilaku itu penting atau tidak. Teori ini juga menegaskan sikap normatif yang mungkin dimiliki oleh seseorang tentang apa yang akan dilakukan orang lain (terutama orang-orang terdekatnya) pada situasi yang sama. Niat berperilaku ditentukan oleh dua faktor utama, yaitu sikap dan norma subjektif.

Menurut (Gelaidin dan Abdullateef, 2016) "Educational support is defined as a set of initiatives designed to improve national economic development through constant investment in quality education bolstered by an adequate number of teachers and relevant learning tools". 
(Suharyat, 2009) menjelaskan bahwa "attitude adalah suatu cara bereaksi terhadap suatu perangsang. Suatu kecenderungan untuk bereaksi terhadap suatu perangsang atau situasi yang dihadapi." Menurut (Jones et al., 2016), "Self-efficacy can be defined as a personal assessment of one's ability to organize and execute behaviors that lead to successful outcomes." Dalam penelitian (Moi et al., 2011), "stated that entrepreneurial intentions can be refer to a state of an individual mind, which directs and guides them toward the development and the implementation of new business concept".

(Lestari dan Wijaya, 2012) dalam penelitiannya menyatakan bahwa pendidikan kewirausahaan berpengaruh signifikan pada intensi berwirausaha. Pendidikan kewirausahaan yang dimaksud ialah proses pembelajaran untuk mengubah sikap dan pola pikir mahasiswa pada pilihan karier berwirausaha. (Adi dan Fahmi, 2017) dalam penelitiannya menyatakan minat berwirausaha pada mahasiswa, diketahui bahwa minat berwirausaha dipengaruhi oleh faktor sikap, yaitu semakin positif sikap terhadap wirausaha, maka semakin tinggi minat berwirausaha pada mahasiswa. Dalam penelitian (Puspitaningtyas, 2017) menunjukkan bahwa efikasi diri berpengaruh secara signifikan terhadap intensi berwirausaha. Tingginya efikasi diri mahasiswa dapat mendorong keinginan untuk memulai suatu usaha, terutama didorong oleh kepercayaan diri yang tinggi. Kepercayaan diri yang tinggi akan memperkuat keyakinan individu untuk mampu berperilaku atau bertindak sesuai dengan yang dikehendaki.

Kerangka pemikiran dalam penelitian ini seperti digambarkan dibawah ini:

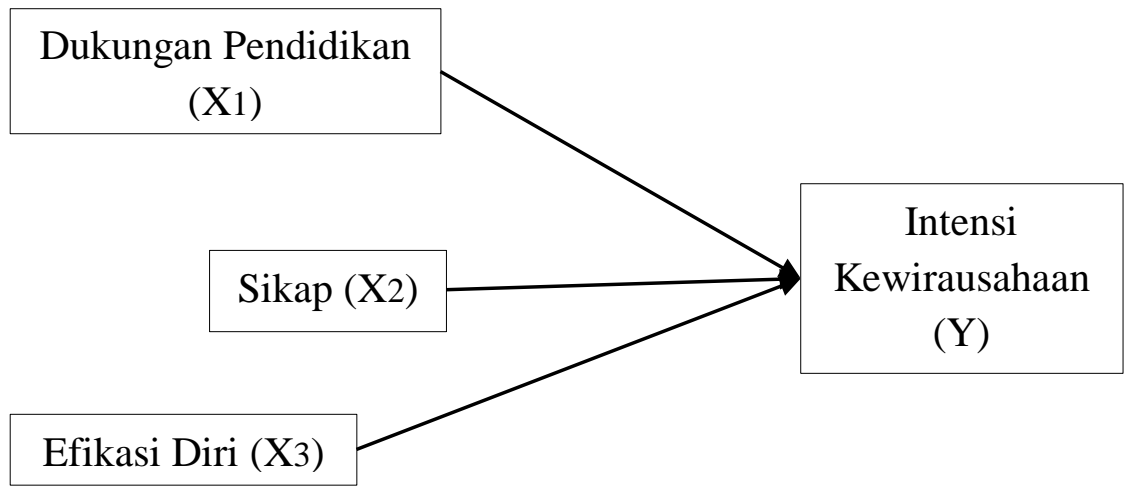

Gambar 1. Kerangka Pemikiran

Hipotesis dari model yang dibangun di atas adalah sebagai berikut:

H1: Terdapat pengaruh Dukungan Pendidikan terhadap Intensi Kewirausahaan pada mahasiswa semester satu Fakultas Ekonomi Universitas Tarumanagara.

H2: Terdapat pengaruh Sikap terhadap Intensi Kewirausahaan pada mahasiswa semester satu Fakultas Ekonomi Universitas Tarumanagara.

H3: Terdapat pengaruh Efikasi Diri terhadap intensi kewirausahaan pada mahasiswa semester satu Fakultas Ekonomi Universitas Tarumanagara.

\section{METODOLOGI}

Dalam penelitian ini, peneliti menggunakan metode penelitian deskriptif karena pada desain penelitian deskriptif ada pengujian tetapi tidak ada variabel yang dimanipulasi (Aritonang, R., 2007). Penelitian ini menggunakan cross-sectional studies, dimana data hanya sekali dikumpulkan, seperti dalam periode harian, mingguan, atau bulanan dalam rangka menjawab rumusan masalah (Sekaran dan Bougie, 2013). Populasi yang digunakan sebagai subjek penelitian ini adalah mahasiswa semester satu Fakultas Ekonomi Jurusan Manajemen 
Universitas Tarumanagara. Metode yang digunakan dalam pemilihan sampel penelitian ini yaitu menggunakan metode nonpropabilitas dengan teknik purposive sampling yang merupakan sampling dimana pengambilan elemen-elemen yang dimasukkan kedalam sampel dilakukan dengan sengaja, dengan catatan bahwa sampel tersebut representative atau mewakili populasi (Supranto, J., 2012).

Jumlah responden yang sesuai dengan pendapat (Roscoe, 1975) ukuran sampel yang layak dalam penelitian yaitu antara 30 sampai 500 orang, apabila sampel memiliki kategori seperti jenis kelamin, kota dan desa, maka setiap anggota berjumlah minimal 30 orang. Penelitian ini memiliki responden dengan karakteristik angkatan 2018 sebanyak 100 (100\%) dari 100 responden. Sebanyak 100 (100\%) dari 100 responden jurusan manajemen. Berdasarkan data yang didapat sebanyak $52(52 \%)$ responden berjenis kelamin wanita dan 48 $(48 \%)$ responden berjenis kelamin pria. Skala yang digunakan dalam penelitian ini ialah skala likert. Skala likert merupakan skala yang digunakan secara luas yang meminta responden menandai derajat kesetujuan atau ketidaksetujuan terhadap masing-masing dari serangkaian pernyataan tentang objek stimulus (Maholtra, 2010).

\section{HASIL UJI STATISTIK}

Tabel 1. Hasil Analisis Average Variance Extracted (AVE)

\begin{tabular}{|c|c|}
\hline Variabel & Average Variance Extracted (AVE) \\
\hline Dukungan Pendidikan & 0,533 \\
\hline Sikap & 0,576 \\
\hline Efikasi Diri & 0,596 \\
\hline Intensi Kewirausahaan & 0,649 \\
\hline
\end{tabular}

Sumber: Pengolahan Data SmartPLS 3.0

Berdasarkan Tabel 1 dapat diketahui bahwa nilai AVE dari setiap variabel memiliki nilai di atas 0,5 dimana telah memenuhi syarat convergent validity yang diukur dari nilai AVE (Hair et al., 2011). Hal ini menunjukkan bahwa setiap variabel-variabel di atas telah memenuhi kriteria convergent validity.

Tabel 2. Hasil Pengujian Validitas

\begin{tabular}{|c|l|c|}
\hline \multicolumn{1}{|c|}{ Indikator } & $\begin{array}{c}\text { Outer Loading } \\
\text { Factor }\end{array}$ \\
\hline DP1 & $\begin{array}{l}\text { Saya telah mendapat bimbingan dan pengajaran } \\
\text { kewirausahaan yang baik di Universitas Tarumanagara }\end{array}$ & 0,779 \\
\hline DP2 & $\begin{array}{l}\text { Untuk memulai sebuah usaha mahasiswa perlu diberikan } \\
\text { mata kuliah kewirausahaan }\end{array}$ & 0,654 \\
\hline DP3 & $\begin{array}{l}\text { Mata kuliah kewirausahaan memberikan saya pengetahuan } \\
\text { yang cukup untuk menjadi seorang wirausaha }\end{array}$ & 0,743 \\
\hline DP4 & $\begin{array}{l}\text { Tugas-tugas yang diberikan kepada saya akan bermanfaat } \\
\text { dalam pengetahuan kewirausahaan }\end{array}$ & 0,629 \\
\hline DP5 & $\begin{array}{l}\text { Tugas praktek memberikan gambaran lingkungan bisnis } \\
\text { yang sebenarnya }\end{array}$ & 0,639 \\
\hline DP6 & $\begin{array}{l}\text { Pelajaran kewirausahaan yang diajarkan di Fakultas } \\
\text { Ekonomi Universitas Tarumanagara sangat jelas }\end{array}$ & 0,781 \\
\hline DP7 & $\begin{array}{l}\text { Metode pembelajaran yang diterapkan di Fakultas } \\
\text { Ekonomi Universitas Tarumanagara sangat baik }\end{array}$ & 0,805 \\
\hline
\end{tabular}




\begin{tabular}{|c|l|c|}
\hline DP8 & $\begin{array}{l}\text { Pelajaran kewirausahaan di Fakultas Ekonomi Universitas } \\
\text { Tarumanagara telah terorganisir dengan baik }\end{array}$ & 0,784 \\
\hline S1 & $\begin{array}{l}\text { Saya lebih suka menjadi pemimpin daripada bekerja } \\
\text { dengan orang lain }\end{array}$ & 0,836 \\
\hline S2 & $\begin{array}{l}\text { Saya lebih suka memulai usaha sendiri daripada bekerja di } \\
\text { tempat lain }\end{array}$ & 0,884 \\
\hline S3 & Penghasilan yang besar itu penting bagi saya & 0,672 \\
\hline S4 & $\begin{array}{l}\text { Saya akan bekerja lebih keras dalam situasi yang } \\
\text { kompetitif }\end{array}$ & 0,609 \\
\hline EF1 & $\begin{array}{l}\text { Saya mempunyai keyakinan dan kepercayaan diri akan } \\
\text { kemampuan sendiri }\end{array}$ & 0,688 \\
\hline EF3 & $\begin{array}{l}\text { Saya mampu menganalisis keyakinan untuk dapat bertahan } \\
\text { dalam mengelola suatu usaha }\end{array}$ & $\begin{array}{l}\text { Saya yakin dapat mengatasi masalah dengan mudah jika, } \\
\text { ada kejadian yang tak terduga }\end{array}$ \\
\hline EF4 & $\begin{array}{l}\text { Saya dapat memikirkan solusi dengan cepat jika sedang } \\
\text { dalam masalah }\end{array}$ & 0,765 \\
\hline EF5 & $\begin{array}{l}\text { Saya mempunyai keyakinan akan berhasil dalam } \\
\text { menjalankan suatu usaha }\end{array}$ & 0,804 \\
\hline EF6 & $\begin{array}{l}\text { Saya dapat mencapai tujuan dengan mudah dalam } \\
\text { berwirausaha }\end{array}$ & 0,801 \\
\hline IK1 & Saya memilih karier sebagai pengusaha & 0,789 \\
\hline IK2 & Saya berniat mendirikan usaha di masa depan & 0,862 \\
\hline IK3 & $\begin{array}{l}\text { Saya lebih suka menjadi wirausahawan daripada menjadi } \\
\text { karyawan di sebuah perusahaan }\end{array}$ & 0,839 \\
\hline IK4 & $\begin{array}{l}\text { Saya ingin mengekspresikan diri dengan bebas dalam } \\
\text { bisnis sendiri }\end{array}$ & $\begin{array}{l}\text { Jika suatu hari saya bisa memulai usaha sendiri itu } \\
\text { merupakan ide yang bagus }\end{array}$ \\
\hline IK5 & 0,728 \\
\hline
\end{tabular}

Sumber: Pengolahan Data SmartPLS 3.0

Berdasarkan hasil di atas menunjukkan bahwa seluruh indikator memiliki nilai loading factor diatas 0,6 dimana telah memenuhi syarat convergent validity (Hair et al., 2011), sehingga dapat disimpulkan jika variabel-variabel di atas telah memenuhi syarat convergent validity yang diukur dari nilai loading factor.

Tabel 3. Hasil Pengujian Reliabilitas

\begin{tabular}{|c|c|c|}
\hline Variabel & Cronbach Alpha's & Composite Realibility \\
\hline Dukungan Pendidikan & 0,873 & 0,901 \\
\hline Sikap & 0,751 & 0,841 \\
\hline Efikasi Diri & 0,864 & 0,898 \\
\hline Intensi Kewirausahaan & 0,861 & 0,901 \\
\hline
\end{tabular}

Sumber: Pengolahan Data SmartPLS 3.0

Berdasarkan tabel uji reliabilitas pada tabel 3 menampilkan hasil pengujian dari empat variabel yang digunakan, diketahui bahwa variabel di atas memiliki nilai cronbach's alpha dan composite realibility di atas 0,7 . Rule of thumb pada nilai alpha/composite realibility harus $>0,7$ meskipun nilai 0,6 masih dapat diterima atau reliabel (Hair et al., 2008). 
Setelah data-data melewati uji outer model pengolahan data variabel-variabel penelitian dilanjutkan pada tahapan pengujian model struktural untuk dapat mengetahui kontribusi dari variabel-variabel independen (X) terhadap variabel-variabel dependen (Y). Berikut merupakan kriteria pengujian model struktural yang harus dipenuhi pada penelitian ini yaitu nilai koefisien determinasi $\left(\mathrm{R}^{2}\right)$, predictive relevance $\left(\mathrm{Q}^{2}\right)$, path coefficients.

Nilai $R$-square juga digunakan umtuk menghitung besarnya peranan atau pengaruh variabel bebas pada variabel tergantung. Koefisien determinasi dihitung dengan cara mengalikan $r^{2}$ dengan $100 \%$ (Sarwono dan Budiono, 2012). Hasil pengujian analisis koefisen determinasi $\mathrm{R}^{2}$ pada penelitian ini adalah sebesar 0,577 berarti bahwa $57,7 \%$ dari variabel dependen yaitu intensi kewirausahaan dapat dijelaskan oleh variabel independen yang terdapat pada penelitian ini dan sisanya yaitu 42,3\% dapat dijelaskan oleh variabel-variabel diluar penelitian ini.. Berdasarkan pendapat yang dikemukakan oleh (Hair et al., 2011), maka nilai Rsquare dalam penelitian ini pengaruhnya tergolong sedang. Uji selanjutnya adalah predictive relevance $\left(\mathrm{Q}^{2}\right)$ dan hasil yang didapatkan adalah $0,352\left(\mathrm{Q}^{2}>0\right)$ yang berarti bahwa konstruk variabel yang terdapat dalam penelitian ini relevan untuk mengukur model penelitian yang telah terbentuk sebelumnya dengan baik. Berdasarkan pendapatan yang dikemukakan (Cohen, 1998), maka nilai predictive relevance $\left(Q^{2}\right)$ dalam penelitian ini tergolong memiliki pengaruh besar. Uji berikutnya adalah Goodness of Fit $(\mathrm{GoF})$, hasilnya yaitu sebesar 0,5892 yang menurut pendapat (Wetzels et al., 2009) bahwa model yang digunakan pada penelitian ini memiliki kecocokan yang besar.

Tabel 4. Hasil Bootstrapping

\begin{tabular}{|l|c|c|c|}
\hline \multicolumn{1}{|c|}{ Variabel } & Path Coefficients & T Statistics & P Values \\
\hline $\begin{array}{l}\text { Dukungan Pendidikan } \rightarrow \\
\text { Intensi Kewirausahaan }\end{array}$ & 0,004 & 0,033 & 0,974 \\
\hline $\begin{array}{l}\text { Sikap } \rightarrow \text { Intensi } \\
\text { Kewirausahaan }\end{array}$ & 0,744 & 7,634 & 0,000 \\
\hline $\begin{array}{l}\text { Efikasi Diri } \rightarrow \text { Intensi } \\
\text { Kewirausahaan }\end{array}$ & 0,032 & 0,271 & 0,786 \\
\hline
\end{tabular}

Sumber: Pengolahan Data SmartPLS 3.0

Berdasarkan tabel di atas hasil pengujian bootstrapping (hipotesis) dari seluruh variabel dengan nilai t-statistics $>1,96$ dan nilai p-values $<0,05$ yang dinyatakan hipotesis tidak ditolak atau dinyatakan signifikan.

Berdasarkan hasil pengujian variabel dukungan pendidikan terhadap intensi kewirausahaan, maka dapat dikatakan bahwa $\mathrm{H} 1$ ditolak karena dukungan pendidikan memiliki nilai t-statistik sebesar 0,033 dan nilai $\mathrm{p}$-values sebesar 0,974 atau $97,4 \%$. Nilai t-statistik tersebut lebih kecil dari pada batas nilai kriteria yaitu 1,96 dan nilai p-values lebih besar dari 0,05 atau $5 \%$. Sehingga dapat disimpulkan bahwa dukungan pendidikan tidak berpengaruh secara signifikan terhadap intensi kewirausahaan.

Berdasarkan hasil pengujian variabel sikap terhadap intensi kewirausahaan, maka dapat dikatakan bahwa $\mathrm{H} 2$ tidak ditolak karena sifat memiliki nilai t-statistik sebesar 7,634 dan nilai p-values sebesar 0,000 atau 0\%. Nilai t-statistik tersebut lebih besar dari pada batas nilai kriteria yaitu 1,96 dan nilai p-values lebih kecil dari 0,05 atau 5\%. Sehingga dapat disimpulkan bahwa variabel sifat dapat berpengaruh secara signifikan intensi kewirausahaan.

Berdasarkan hasil pengujian variabel efikasi diri terhadap intensi kewirausahaan, maka dapat dikatakan bahwa $\mathrm{H} 3$ ditolak karena efikasi diri memiliki nilai t-statistik sebesar 0,271 dan nilai p-values sebesar 0,786 atau 78,6\%. Nilai t-statistik tersebut lebih kecil dari pada batas nilai kriteria yaitu 1,96 dan nilai p-values lebih besar dari 0,05 atau 5\%. Sehingga dapat 
disimpulkan bahwa efikasi diri tidak berpengaruh secara signifikan terhadap intensi kewirausahaan.

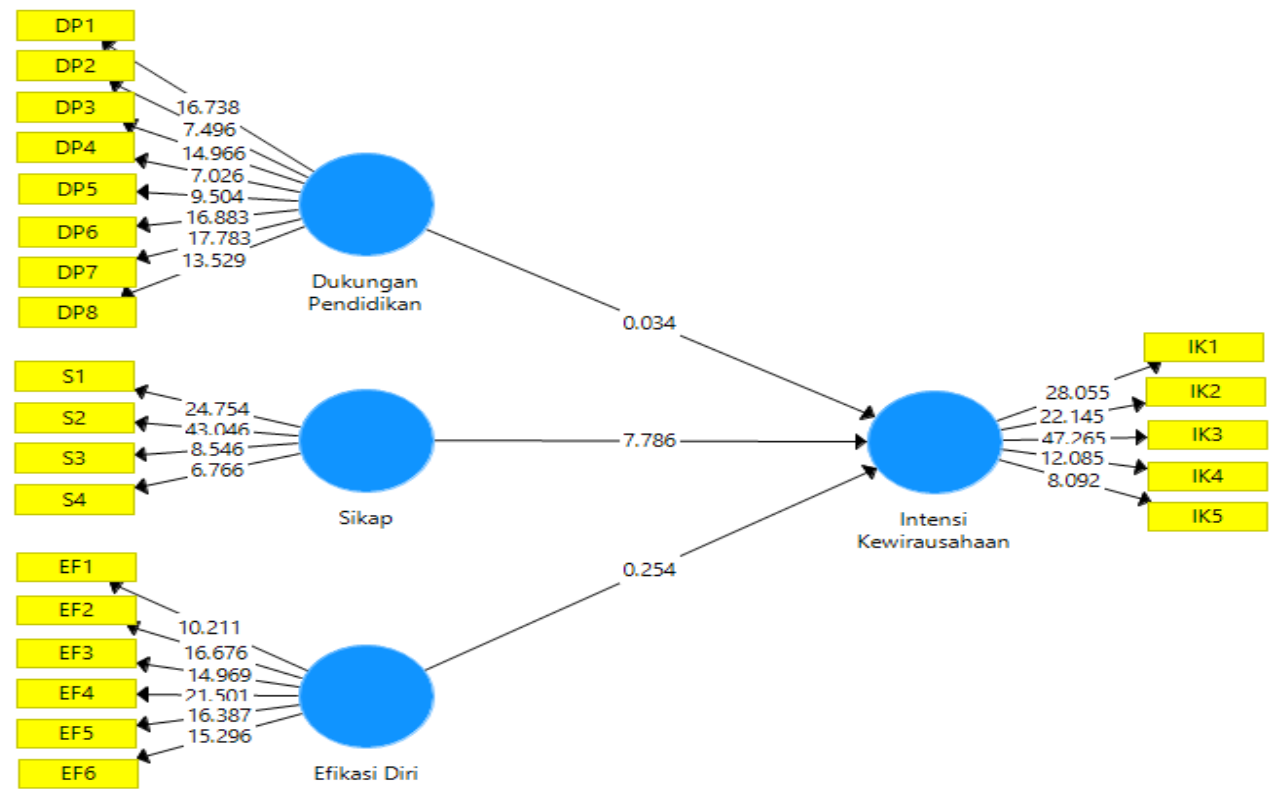

Sumber: Pengolahan Data SmartPLS 3.0

Gambar 2. Hasil Pengujian Bootstrapping

\section{DISKUSI}

Hasil dari pengujian hipotesis menunjukkan tidak terdapat pengaruh yang signifikan antara variabel dukungan pendidikan terhadap intensi kewirausahaan pada mahasiswa semester satu Fakultas Ekonomi Jurusan Manajemen Universitas Tarumanagara. Pada variabel sikap terdapat pengaruh yang signifikan terhadap intensi kewirausahaan pada mahasiswa semester satu Fakultas Ekonomi Jurusan Manajemen Universitas Tarumanagara sedangkan pada variabel efikasi diri tidak terdapat pengaruh yang signifikan terhadap intensi kewirausahaan pada mahasiswa semester satu Fakultas Ekonomi Jurusan Manajemen Universitas Tarumanagara.

\section{PENUTUP}

Berdasarkan hasil pengujian data dalam penelitian ini, menunjukkan bahwa dukungan pendidikan tidak terdapat pengaruh yang signifikan terhadap intensi kewirausahaan pada mahasiswa semester satu Fakultas Ekonomi Jurusan Manajemen Universitas Tarumanagara, hal ini kemungkinan bahwa mahasiswa semester satu masi terlalu dini untuk menyadari pentingnya pendidikan kewirausahaan untuk menjalankan usaha, sedangkan sikap terdapat pengaruh yang signifikan terhadap intensi kewirausahaan pada mahasiswa semester satu Fakultas Ekonomi Jurusan Manajemen Universitas Tarumanagara, sikap pada mahasiswa Fakultas Ekonomi Universitas Tarumanagara sudah baik tetapi hendaknya lebih dapat diperhatikan sebagai bahan pertimbangan dalam proses penelitian selanjutnya, efikasi diri tidak terdapat pengaruh yang signifikan terhadap intensi kewirausahaan pada mahasiswa semester satu Fakultas Ekonomi Jurusan Manajemen Universitas Tarumanagara, hal ini dapat terjadi dikarenakan mahasiswa semester satu yang pengalaman atau pengetahuan tentang berwirausaha masih minim sehingga berkurangnya juga rasa percaya diri dalam memulai sebuah usaha sehingga universitas harus terus memperhatikan dan meningkatkan efikasi diri 
pada mahasiswa. Hal ini dimaksudkan agar dapat memperkuat minat mahasiswa untuk berwirausaha sehingga setelah lulus, para mahasiswa menjadi lebih yakin dan mampu mewujudkannya minatnya untuk berwirausaha.

Keterbatasan dari penelitian ini dikarenakan: (1) Penelitian ini hanya menggunakan 3 variabel independen, (2) Sampel yang digunakan hanya sebanyak 100 responden dan hanya pada mahasiswa semester satu Fakultas Ekonomi Jurusan Manajemen, (3) Penelitian ini hanya dilakukan pada satu kawasan yaitu Universitas Tarumanagara.

Berdasarkan hasil dan keterbatasan di atas, maka saran yang dapat diberikan untuk melakukan penelitian selanjutnya adalah dengan menambahkan variabel independen lainnya yang mempengaruhi intensi kewirausahaan seperti variabel locus of control dan kreativitas, jangkauan dalam pengambilan sampel dan daerah yang akan diteliti diperluas lagi untuk dapat memperkuat dan melengkapi penelitian sebelumnya, dan untuk peneliti selanjutnya mungkin bisa meneliti kembali angkatan 2018 pada semester akhir mereka.

\section{DAFTAR PUSTAKA}

Adi, F., Sumarwan, U., dan Fahmi, I. (2017). Pengaruh Faktor Sikap, Norma Subjektif, Demografi, Sosioekonomi serta Literasi Keuangan Syariah dan Konvensional terhadap Minat Berwirausaha pada Mahasiswa. Al-Muzara'ah, 5(1), 1-20.

Aritonang R., Lerbin R. (2007). Riset pemasaran. Teori \& praktik. Bogor: Ghalia Indonesia.

Cohen, Jacob. (1988). Statiscal Power Analysist for the Behavioral Sciences (Ed. 2). Hillsdale: Erlbaum Associates.

Fishbein and Ajzen, Icek. (1975). Belief, attitude, intention, and behavior: An introduction to theory and research. Reading, MA: Addison-Wesley Publishing Company.

Gelaidan, H. M., and Abdullateef, A. O. (2016). Entrepreneurial intentions of business students in Malaysia: the role of self-confidence, educational and relation support. Journal of Small Business and Enterprise Development, 24(1), 54-67.

Hair, J. F. Jr., Anderson, R. E., Tatham, R. L. and Black, W. C. (2008). Multivariate Data Analysis. New Jersey: Prentice-Hall

., Ringle, C. M., and Sarstedt, M. (2011). PLS-SEM: Indeed A Silver Bullet. The Journal of Marketing theory and Practice, 19(2), 139-152.

Jones, D., M.P.H., Thomas-Purcell, K., Lewis-Harris, J., and Richards, Christine,M.P.H., PhD. (2016). Correlation between self-efficacy in sexual negotiation and engagement in risky sexual behaviors: Pilot study of adolescents attending a secondary school in grenada, west indies. International Public Health Journal, 8(3), 397-405.

Lestari, R.B dan Trisnadi Wijaya. (2012). Pengaruh Pendidikan Kewirausahaan Terhadap Minat Berwirausaha Mahasiswa di STIE MDP, STMIK MDP, dan STIE MUSI. Jurnal Ilmiah STIE MDP, 1(2): 112-119.

Malhotra, N. K. (2012). Basic marketing research: Integration of social media. Boston, MA: Pearson.

Moi, Adeline dan Dyana (2011). Young adult responses to entrepreneurial intent. Refreed Research Journal, 2(3), 37-52.

Puspitaningtyas, Z. (2017). Pengaruh efikasi diri dan pengetahuan manajemen keuangan bisnis terhadap intensi berwirausaha. JWEM (Jurnal Wira Ekonomi Mikroskil), 7(2), 141-150.

Roscoe, J. T. (1975). Fundamental research statistics for the behavioral sciences ( ${ }^{\text {nd }}$ Edition), New York: Holt, Rinehart and Winston.

Sarwono, Jonathan dan Budiono, Herlina. (2012). Statistika Terapan: Aplikasi (Untuk Riset Skripsi, Tesis dan Disertasi Menggunakan SPSS, AMOS dan Excel). Jakarta: PT Elex Media Komputindo. 
Sekaran, U., and Bougie, R. (2013). Research methods for business: A skill building approach. United Kingdom: John Wiley \& Sons Ltd.

Suharyat, Y. (2009). Hubungan antara sikap, minat dan perilaku manusia. REGION, 1(2), 1-9.

Sumarsono, H. (2013). Faktor-faktor yang Mempengaruhi Intensi Wirausaha Mahasiswa Universitas Muhammadiyah Ponorogo. Ekuilibrium: Jurnal Ilmiah Bidang Ilmu Ekonomi, 8(1), 62-88.

Supranto, J. (2012). Metode Riset: Aplikasi dalam Pemasaran. Edisi Ketujuh/Revisi. Jakarta: Rineka Cipta.

Wetzels, M., Odekerken-Schroder, G., and van Oppen, C. (2009). Using PLS path modeling for assessing hierarchical construct models: Guidelines and empirical illustration, $M I S$ Quarterly, 33(1), 177-195. 